\title{
Galactosylated poly-L-lysine targeted microbubbles for ultrasound mediated antisense $c-m y c$ gene transfection in hepatocellular carcinoma cells
}

\author{
Hui Jing, Wen Cheng, Jiu-Wei Zhang, Xue Han, Hua Shao, Yi-Xin Sun
}

Department of Ultrasound, Harbin Medical Univeristy Cancer Hospital, Harbin, China

Submitted: 1 August 2013

Accepted: 24 September 2013

Arch Med Sci 2015; 11, 2: 292-300

DOI: 10.5114 /aoms.2015.50963

Copyright $\odot 2015$ Termedia \& Banach

\section{Abstract}

Introduction: The aim of the study was to investigate the efficiency of delivery and targeted binding of c-myc antisense oligodeoxynucleotide (ASODN) and find a novel therapy for hepatic carcinoma.

Material and methods: A targeted ultrasound microbubble compound was synthesized to deliver the c-myc ASODN by ultrasound-targeted microbubble destruction (UTMD) and applied in hepatocellular carcinoma cells (HCC) and cancer bearing mice. Lipid microbubbles were conjugated with biotinylated galactosylated poly-L-lysine (G-PLL) and SonoVue to target the hepatocellular carcinoma SMMC7721 cells with asialoglycoprotein receptors. There were four groups in both in vitro and in vivo studies: control group (group A); c-myc ASODN + G-PLL (CG group, group B); c-myc ASODN + SonoVue (CUS group, group C); c-myc ASODN + G-PLL + SonoVue (CGUS group, group D). The expression of c-myc mRNA was detected by reverse transcription-polymerase chain reaction (RT-PCR), and proliferation investigations of the SMMC7721 cells were also performed. In addition, the tumor volume was calculated and compared among different groups.

Results: The level of c-myc mRNA in the three experimental groups was significantly lower than that in the control group in vitro $(p<0.05)$. Furthermore, $c$-myc gene expression was suppressed more strongly in the CGUS group compared with other groups in both in vitro and in vivo studies $(p<0.05)$. In addition, ultrasound mediation of targeted microbubbles yielded the highest inhibition of tumor growth and cell proliferation among the four groups.

Conclusions: The use of a G-PLL targeted microbubble contrast agent combined with ultrasound exposure could be a potential method for increasing gene delivery efficiency. This technique is a promising nonviral approach that can be used in liver cancer.

Key words: C-myc, antisense oligodeoxynucleotide, galactosylated poly-Llysine, microbubble, hepatocellular carcinoma cell.

\section{Introduction}

Hepatocellular carcinoma (HCC) is one of the most common and lethal primary malignant tumors worldwide [1]. The best treatment options with curative intention for HCC are surgical resection and liver transplantation. However, most patients with advanced HCC are not amenable to surgical resection or transplantation [2]. In recent years, a variety of inter-

\author{
Corresponding author: \\ Wen Cheng \\ Department of Ultrasound \\ Harbin Medical Univeristy \\ Cancer Hospital \\ 150 Haping Road \\ Nangang District \\ 150081 Harbin, China \\ Phone: +862158609462 \\ E-mail: chengwen69@yahoo. \\ com
}


ventions have been developed, such as percutaneous ethanol injection (PEI), transcatheter arterial embolization (TAE), microwave heat-induced thermotherapy (HiTT) and laser-induced thermotherapy (LiTT) [3]. Nevertheless, the recurrence rate of liver tumor after the resection is relatively high, and tumor cells tend to transfer along the needle tract [4].

With the development of biotechnology, gene therapy is becoming a new strategy for treating cancer. However, the safety and efficacy of gene delivery systems have hampered its clinical application. The vectors used for gene therapy can be divided into viral vectors and non-viral vectors. $\mathrm{Vi-}$ ral vectors can provide high transfection efficiency, but the uncertain outcome and up-regulated immune responses after transfection make it difficult to achieve stable and lasting expression [5]. In contrast, non-viral vectors are much safer, but are limited by lower transfection efficiency [6]. Therefore, one of the most critical tasks in this field is to find an optimal gene delivery system, which can overcome the limitations of both viral and non-viral gene delivery systems.

Microbubble contrast agent is a new gene carrier, which adheres or parcels therapeutic genes and can significantly increase the gene transfection efficiency and expression [7, 8]. A microbubble is a gas-filled microsphere with a diameter of 3-5 $\mu \mathrm{m}$. Its shell or lumen is attached or encapsulated with the bioactive substance $[9,10]$. After being exposed to ultrasonic irradiation, the cell membrane permeability can be transiently enhanced, and gene transfer can be further facilitated through the production of small and nonlethal pores in cell membranes. This biophysical process is called sonoporation [11, 12]. Thereby, genes carried by microbubbles can be administered intravenously and directly to the targeted tissue. In addition, gene delivery should be limited to the targeted region, and delivery to non-targeted cells should be avoided [13]. More recently, ultrasound-targeted microbubble destruction (UTMD) has evolved as a novel gene transfection method with high transfection efficiency and safety [14-16].

The surface of a liver cell has asialoglycoprotein receptors (ASGP-Rs), which specially recognize and endocytose glycoproteins with terminal galactose groups, known as galactose-specific receptors [17]. Galactosylated poly-L-lysine (G-PLL) has been used as a targeting ligand for ASGP-R and can promote the expression of the plasmid in the liver cell [18]. In addition, it was found that the c-myc oncogene was an essential early gene in cell proliferation and played an important role in the formation and development of hepatocellular carcinoma [19]. The transcription of the c-myc gene can be interrupted by c-myc antisense oligodeoxy- nucleotide (ASODN), which can further suppress the proliferation of cells.

In the present study, we applied intravenous administration of microbubbles combined with ultrasonic irradiation to investigate the transfection efficiency of c-myc ASODN and its association with cell proliferation and tumor inhibition rate. To the best of the authors' knowledge, there is limited information so far on using targeted UTMD mediated delivery of c-myc ASODN to HCC.

\section{Material and methods}

\section{Cell culture}

SMMC7721 cells, a human HCC cell line, were kindly donated by the Institute of Cancer Research (affiliated with Harbin Medical University) and were maintained in RPMI-1640 media (Invitrogen, Carlsbad, CA) supplemented with $10 \%$ fetal bovine serum (Invitrogen), $100 \mathrm{U} / \mathrm{ml}$ penicillin and $100 \mu \mathrm{g} / \mathrm{ml}$ streptomycin. Cells were cultured in a humidified atmosphere containing $5 \% \mathrm{CO}_{2}$ at $37^{\circ} \mathrm{C}$. The cells were routinely passaged every 2 days. The total cell count was determined with a hemocytometer (Bürker-Türk, Wertheim, Germany). Exponentially growing cells were used for all experiments. The local ethics committee of Harbin Medical University has approved the protocol for using the donated human HCC lines in the experimental study.

\section{Animal model}

The study protocol was also approved by the Animal Research Committee of Harbin Medical College. Male BALB/c mice (nu/nu, 4-6 weeks, weight 18-22 g) were obtained from the Experimental Animal Research Center. SMMC7721 cells were harvested to prepare single cell suspensions at $2 \times 10^{6} / \mathrm{ml}$ cell concentration. All mice were fixed and inoculated subcutaneously with $0.2 \mathrm{ml}$ of SMMC7721 cells. Time and size of tumor formation were recorded. After 10 days, the tumors reached a size of $5-10 \mathrm{~mm}$ and the experiments were initiated.

\section{Design of c-myc ASODN sequence}

The c-myc antisense oligonucleotide (ASODN) was synthesized according to the second exon start code AUG and thereafter codon 4 of c-myc mRNA. The sequence is 5'-AAC GTT GAG GGG CAT-3', and the ASODN was modified by phosphorothioate and biotinylated (Biological Engineering Company, Shanghai).

\section{Preparation of biotinylated G-PLL}

A total of $113.2 \mathrm{mg}$ of poly-L-lysine, $480.5 \mathrm{mg}$ of lactose and $300.0 \mathrm{mg}$ of sodium borohydride 
were dissolved in $120 \mathrm{ml}$ of $\mathrm{H}_{2} \mathrm{O}$, and stirred at $37^{\circ} \mathrm{C}$ for $24 \mathrm{~h}$; then the solution was adjusted to $\mathrm{pH} 8.5$ with $5 \mathrm{~mol} / / \mathrm{l}$ of $\mathrm{KOH}$, and then stirred for $6 \mathrm{~h}$. The solution was dialyzed and purified with running water, and finally dried to collect the pure G-PLL product. $1 \mathrm{mg} / \mathrm{ml}$ biotin (B-NHS) was prepared with dimethylformamide (DMF), and $1 \mathrm{mg} / \mathrm{ml} \mathrm{G}$-PLL was prepared with $\mathrm{pH} 9.6$ carbonate buffer, then the B-NHS and G-PLL were mixed and shaken for $2 \mathrm{~h}$, and the biotinylated G-PLL was generated through dialysis at $4^{\circ} \mathrm{C}$. Then the biotinylated G-PLL and non-biotinylated G-PLL were labeled with fluorescein isothiocyanate (FITC, Sigma, USA) and added to the plate coated with streptavidin.

\section{Preparation of biotinylated SonoVue}

SonoVue contains sulfur hexafluoride gas and has a phospholipid monolayer shell. The suspension of SonoVue microbubbles was reconstituted immediately before use by a bolus injection of $5 \mathrm{ml}$ of $0.9 \%$ saline solution. The mean diameter of the microbubbles was $2.5 \mu \mathrm{m}$, and the concentration was from $2 \times 10^{8}$ to $5 \times 10^{8}$ microbubbles $/ \mathrm{ml}$. The DSPE-PEG2000-Biotin powder was dissolved in PBS, and $1 \mathrm{ml}$ of microbubble suspension was added, and then shaken, and washed to prepare biotinylated microbubbles. Next, the streptavidin plate was inverted in the biotinylated microbubble suspensions for $30 \mathrm{~min}$, washed with PBS 3 times and observed under a microscope; at the same time, ordinary microbubbles were set as a control.

\section{Synthesis of G-PLL targeted ultrasound microbubble compounds}

ASODN and G-PLL were mixed respectively in the same volume and different molar ratios ( $1: 1,1: 2,1: 3$ and $1: 4)$. Then, the final concentration of c-myc ASODN was $10 \mu \mathrm{mol} / \mathrm{l}$, and the mixture was incubated for $2 \mathrm{~h}$, and then was added to SMMC-7721 cells. After $24 \mathrm{~h}$, the distribution of c-myc ASODN and G-PLL conjugate on the cell surface was observed under an inverted fluorescence microscope to determine the optimal ratio. The following compounds were prepared: c-myc ASODN + G-PLL; SonoVue + c-myc ASODN; SonoVue + c-myc ASODN + G-PLL.

\section{Ultrasound exposure}

Ultrasound was delivered using an Acuson Sequoia 512 ultrasound system (Siemens Medical Solutions, Mountain View, CA) with 4C1-S transducer in the contrast pulse sequence mode. The parameters were evaluated and described as previously reported [20]. The cells were exposed at $1.0 \mathrm{~W} / \mathrm{cm}^{2}$ intensity, $10 \%$ duty cycles and $1.5 \mathrm{MHz}$ continuous ultrasound for $60 \mathrm{~s}$.

\section{Gene transfection experiments in vitro}

The SMMC-7721 cells were maintained in serum-free medium for $24 \mathrm{~h}$, and then the flask was coated with a coupling agent and exposed to ultrasonic irradiation. There were four groups $(n=5)$, and $500 \mu \mathrm{l}$ of the following substances were added to cells: control group (group A); c-myc ASODN + G-PLL (CG group, group B); c-myc ASODN + SonoVue (CUS group, group C); c-myc ASODN + G-PLL + SonoVue (CGUS group, group D). Both group $C$ and $D$ were exposed to ultrasonic irradiation in vitro and in vivo, respectively. Cells were collected at $24 \mathrm{~h}$ after the end of the experiment.

\section{3-(4,5-Dimethylthiazol-2-yl)-2,5- diphenyltetrazolium bromide cell proliferation assay}

For the 3-(4,5-dimethylthiazol-2-yl)-2,5-diphenyltetrazolium bromide (MTT) cell proliferation assay, cells $\left(1.5 \times 10^{4}\right.$ per well) were seeded into 96-well plates in triplicate and transiently transfected the next day. After 0, 24, 48 and 72 h, $100 \mu \mathrm{l}$ of MTT was added to each well, and the plates were incubated for $4 \mathrm{~h}$ at $37^{\circ} \mathrm{C}$, then the medium was removed, and MTT crystals were solubilized in dimethylsulfoxide, after which the spectrophotometric absorbance of each sample was measured at $490 \mathrm{~nm}$ using a Glomax $96 \mathrm{mi}-$ croplate luminometer and analyzed using Microplate Manager (Promega Corp, Madison, WI).

\section{Gene transfection experiments in vivo}

Tumor formation was observed 10 day after inoculation in 20 nude mice, and the tumor diameter detected by routine ultrasound was more than $0.5 \mathrm{~cm}$. Nude mice were randomly divided into four groups $(n=5)$ : PBS (control group, group A); c-myc ASODN + G-PLL (CG group, group B); c-myc ASODN + SonoVue (CUS group, group C); c-myc ASODN + G-PLL + SonoVue (CGUS group, group D). Groups $C$ and D were exposed to ultrasound with the same mechanical parameters as in vitro experiments, but the ultrasonic time was prolonged by $5 \mathrm{~min}$. The concentration of c-myc ASODN in the microbubble compound was $20 \mu \mathrm{mol} / \mathrm{l}$. All animals were injected with $200 \mu \mathrm{l}$ of transfection medium through the caudal vein using a $0.5 \mathrm{ml}$ insulin syringe. The tumor volume was observed by routine ultrasound, and the diameter of the tumor was measured 4 times daily every 7 day. All mice were sacrificed at 28 day, and the tumor was removed and stored in liquid nitrogen. The tumor volume and tumor inhibition rate were calculated. Tumor inhibition rate $=($ (mean tumor volume of control group-mean tumor volume of experimental group)/mean tumor volume of control group) $\times$ $100 \%$. Tumor volume $=(\varpi / 6) \times$ long diameter $(\mathrm{a})$ 
$\times$ short diameter $(b)$, and the growth curve of the tumor was drawn according to the tumor volume.

\section{Semiquantitative RT-PCR}

The cells were harvested $24 \mathrm{~h}$ after transfection, and semiquantitative RT-PCR was performed to determine the mRNA expression of c-myc. Total RNA was extracted with an RNA isolation kit (Watson, Shanghai, China) according to the manufacturer's instructions both for in vitro and in vivo study. The RNA was reverse transcribed to cDNA with a reverse transcription kit (Takara, Dalian, China). The resultant cDNA was amplified using a specific primer pair for c-myc: forward, 5'- TAC ATC CTG TCC GTC CAA GCA -3'; and reverse, 5'- TCA GCC AAG GTT GTG AGG TTG -3', which yielded a predicted amplicon of 260 base pairs. $\beta$-actin was used as an internal standard, and its mRNA was amplified with the following primers: forward, 5'- CTC CAT CCT GGC CTC GCT GT -3'; and reverse, 5'- GCT GTC ACC TTC ACC GTT CC -3', in a similar fashion, which yielded a predicted amplicon of 460 base pairs. The following cycling program was used for RT-PCR: denaturing at $94^{\circ} \mathrm{C}$ for $2 \mathrm{~min}$, 35 cycles (denaturation at $94^{\circ} \mathrm{C}$ for $30 \mathrm{~s}$, renaturation at $60^{\circ} \mathrm{C}$ for $30 \mathrm{~s}$, and extension at $72^{\circ} \mathrm{C}$ for $30 \mathrm{~s}$ ), and final extension at $72^{\circ} \mathrm{C}$ for $7 \mathrm{~min}$. After electrophoresis, the bands were visualized using a Bio-Rad GelDoc 2000 gel imaging system (BioRad, CA, USA) and were analyzed using semiquantitative software. The relative expression of $c-m y c$ was calculated as the ratio of $c-m y c$ and $\beta$-actin. Inhibition rate $=$ (control group-experimental group)/control group $\times 100 \%$.

\section{Statistical analysis}

Statistical analyses were performed with SPSS 14.0 software (SPSS Inc, Chicago, IL). Linear regression was performed on the preparation and analysis of G-PLL. The measurements were expressed as mean \pm standard deviation. Measurement differences among groups were determined by an analysis of variance (ANOVA). The comparison of the

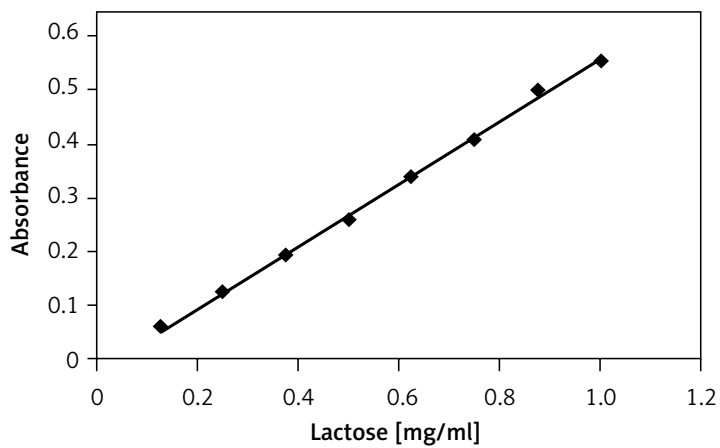

Figure 1. Standard curve of lactose in G-PLL transfection rate was performed using the LSD $t$ test. Significance was defined as $p<0.05$, with the Bonferroni correction for multiple comparisons.

\section{Results}

\section{Preparation and analysis of G-PLL}

The composition of the synthetic product was analyzed with a UV spectrophotometer, and the regression equation was calculated as the absorbance $(A)$ and concentration $(C)$ of lactose, $A=$ $57.400^{\star} \mathrm{C}-0.018(r=0.9979)$ (Figure 1). According to the value of absorbance, the concentration of lactose was $16.59 \%$ in the sample. The molar ratio of lactose to poly-L-lysine was $24: 1$, and the average molecular weight of G-PLL was 48000 . The results of infrared spectroscopic analysis showed that lactose and poly-L-lysine formed a covalent compound (Figure 2).

\section{The coupling effect of microbubbles and} biotin, G-PLL and biotin

The streptavidin plate was observed under a microscope (400x), and the results showed that the number of microbubbles was significantly higher in the biotinylated group than that in the non-biotinylated group (Figure 3). Bright green fluorescence was also observed in the biotinylated G-PLL labeled with FITC, while there was no fluorescence in the control group (Figure 4).

\section{The ratio of c-myc ASODN and G-PLL}

The c-myc ASODN and G-PLL conjugates gathered on the surface of SMMC7721 cells in the form of small blisters; with the increase of G-PLL concentration, the aggregation on the cell surface reached the saturated platform, and conjugates accumulated greatly in the medium (Figure 5). After the dead cells were removed, the conjugates gathered on the cell surface and displayed a yellow-green fluorescence. Based on levels of fluorescence, we determined that the optimal molar ratio of c-myc ASODN to G-PLL was $1: 2$ (Figure 6).

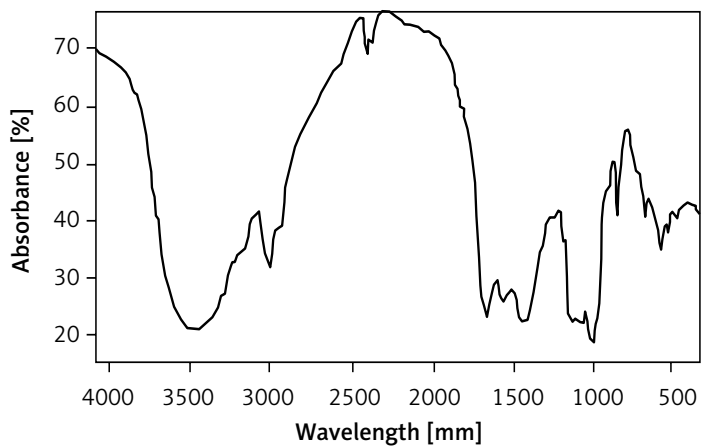

Figure 2. Infrared spectra of G-PLL. The absorption peak means the C-N covalent of G-PLL 

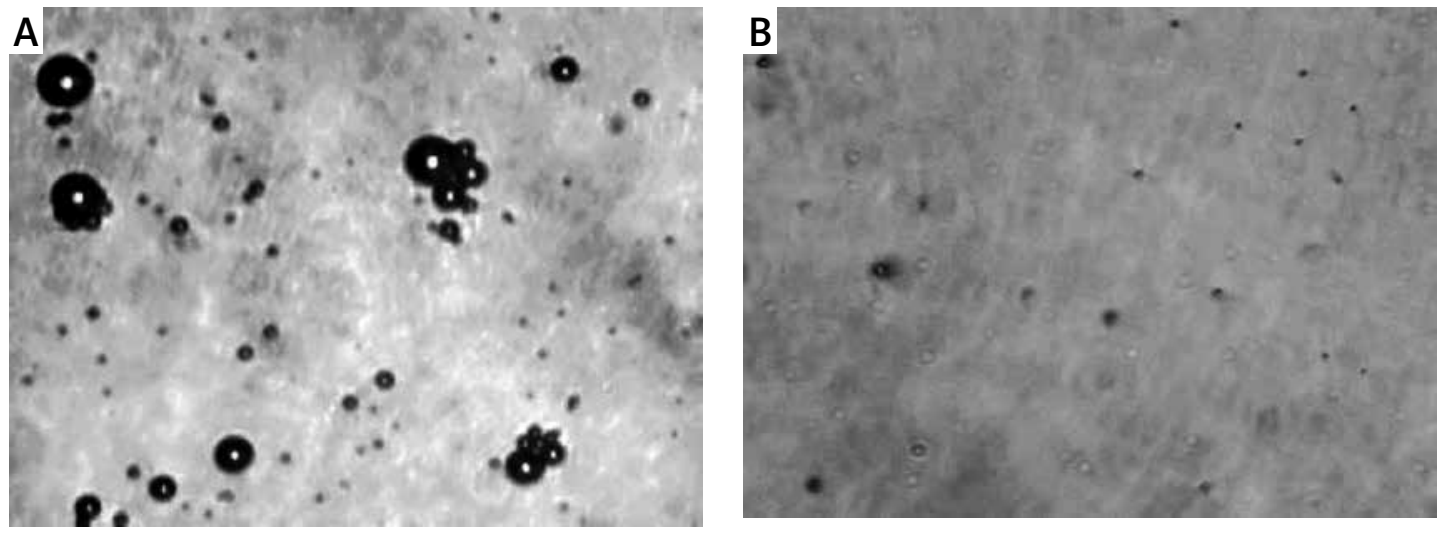

Figure 3. Under the optical microscope, it could be observed that the microbubbles were much more numerous in the biotinylated group than in the non-biotinylated group. A - Microbubbles in biotinylated group; B - microbubbles in non-biotinylated group (400x)
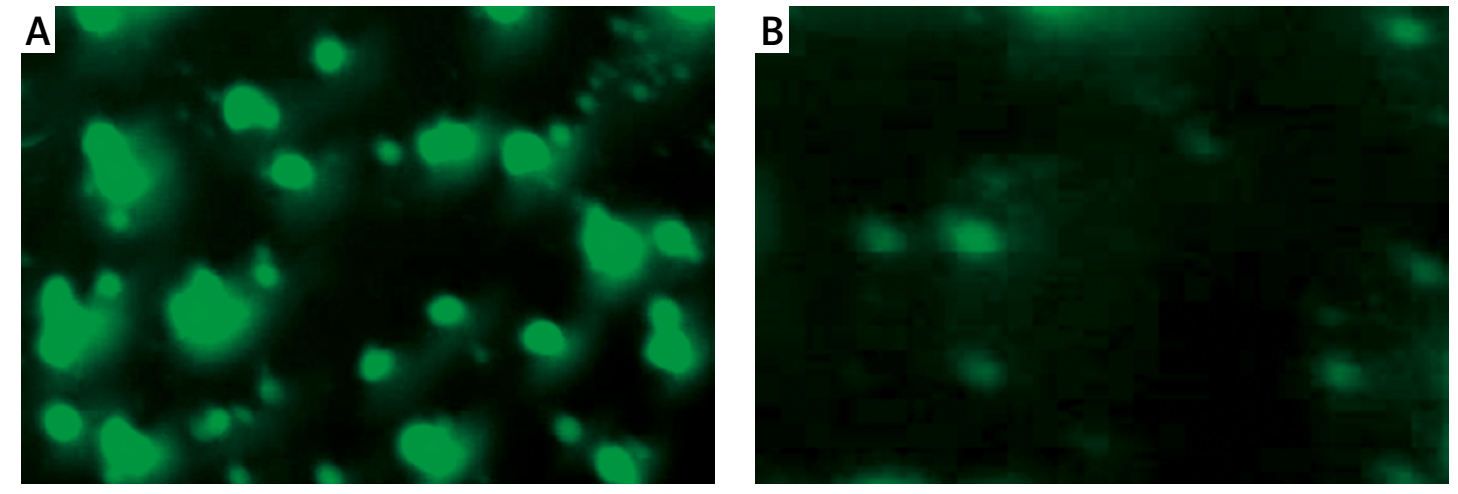

Figure 4. Under the fluorescence microscope, bright green fluorescence was observed in B-NHS labeled G-PLL, while there was no obvious fluorescence in the only FITC labeled G-PLL group. A - G-PLL photofluorogram marked by both B-NHS and FITC; B - G-PLL photofluorogram marked only by FITC (400×)
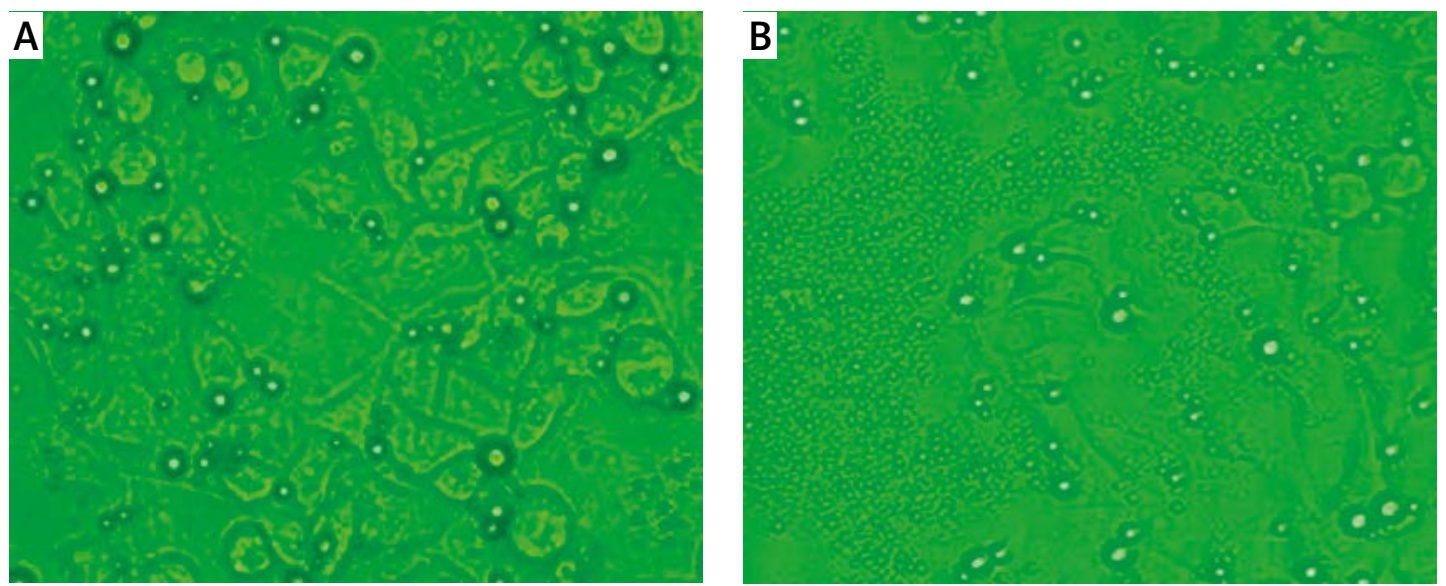

Figure 5. Distribution of c-myc ASODN and G-PLL conjugates on the cell surface (400x). A - Conjugates gathered on the cell surface $(1: 2)$; B - Conjugates accumulated greatly in the medium $(1: 3$ and $1: 4)$

\section{Proliferation levels of different groups}

The proliferation levels of the different experimental groups of SMMC-7721 cells are shown in Figure 7. The results showed that the cell proliferation was not significantly different between groups before $24 \mathrm{~h}(p>0.05)$. At 48 and $72 \mathrm{~h}$ after transfection, the proliferation levels of the three experimen- tal groups were significantly inhibited compared with the control group $(p<0.05)$. Furthermore, the proliferation in the CGUS group was markedly decreased compared to the CG and CUS group $(p<0.05)$. These results indicate that the efficiency of proliferation inhibition increased significantly in a time-dependent manner between 24 and $72 \mathrm{~h}$. 

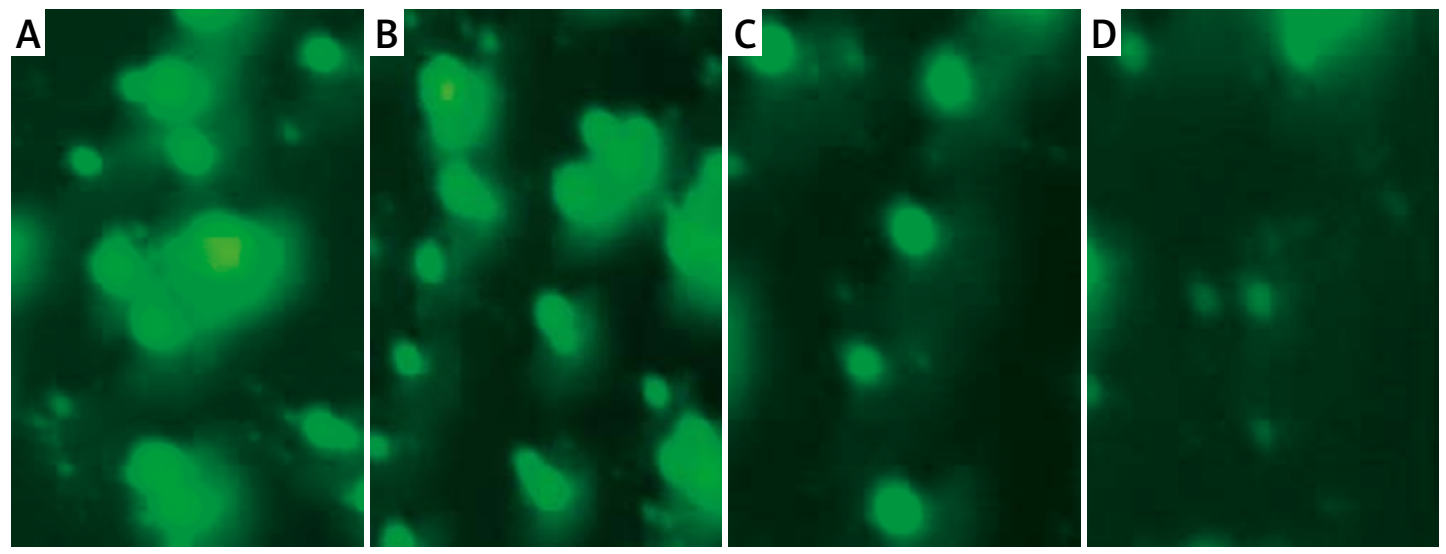

Figure 6. A-c-myc ASODN : G-PLL = 1: 1; B - c-myc ASODN : G-PLL = 1:2; C - c-myc ASODN : G-PLL = 1:3; $D-c-m y c$ ASODN : G-PLL $=1: 4$. With the different ratio of $c-m y c$ ASODN to G-PLL, the amount of fluorescence was different on the cell surface

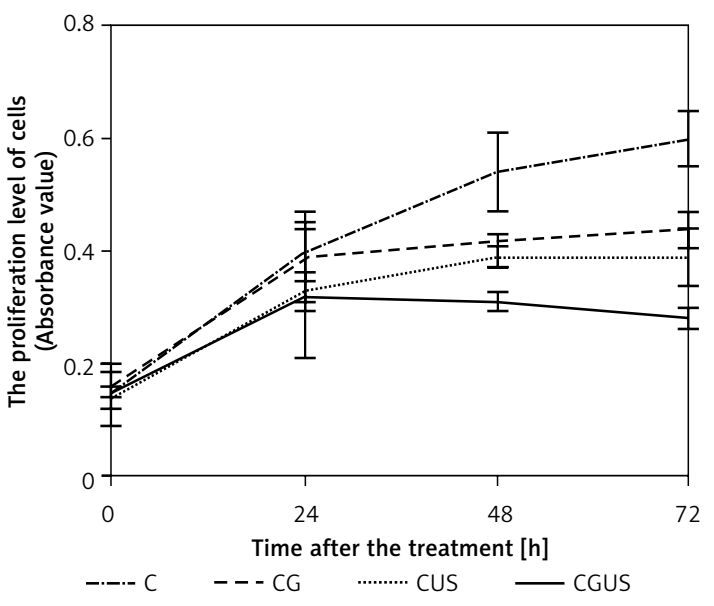

Figure 7. Curves of cell proliferation

\section{Growth inhibition of subcutaneously transplanted tumor}

The results showed that the tumor volume of group A was significantly greater than that of other groups ( $p<0.05$, Table I). In the same time period, the tumor volume of group $D$ was significantly smaller than that of other groups at each time point and the tumor inhibition rate was 39.3 $\pm 5.2 \%$, suggesting that the tumor growth was most inhibited in group D (Figure 8).

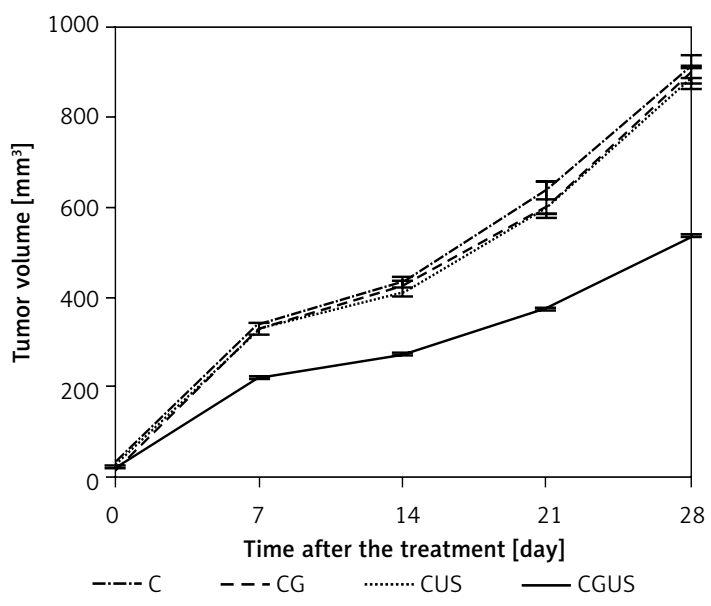

Figure 8. Curves of tumor growth

\section{Inhibition of c-myc gene expression}

The c-myc ASODN was transfected in four experimental conditions in vitro and in vivo, respectively. Semiquantitative RT-PCR analysis (Figure 9) showed that the inhibition rates of c-myc mRNA in groups CG, CUS, and CGUS were $2.35 \pm 0.54 \%$, $5.99 \pm 1.90 \%$ and $30.84 \pm 2.26 \%$ in vivo, and 23.91 $\pm 1.7 \%, 23.93 \pm 2.6 \%$ and $45.52 \pm 0.9 \%$ in vitro, respectively (Table $\mathrm{I}$ ), indicating that the CGUS group was more efficient in suppressing c-myc

Table I. Gross tumor volume of four groups of cancer bearing mice

\begin{tabular}{|lcccccc|}
\hline Groups & \multicolumn{5}{c}{ Tumor volume after treatment $\left[\mathrm{mm}^{3}\right]$} & \multicolumn{2}{c|}{\begin{tabular}{c} 
Tumor \\
inhibition rate \\
\cline { 2 - 6 }
\end{tabular}} & $\mathbf{0}$ day & $\mathbf{7}$ days & $\mathbf{1 4}$ days & 21 days & 28 days & (\%) \\
\hline A & $21.6 \pm 1.2^{\Delta}$ & $341.6 \pm 3.9$ & $436.2 \pm 7.5$ & $636.1 \pm 17.6$ & $911.5 \pm 22.4^{\#}$ & 0 \\
\hline B & $18.9 \pm 1.3^{\Delta}$ & $326.1 \pm 7.9$ & $423.2 \pm 10.1$ & $602.0 \pm 15.0$ & $893.3 \pm 19.8$ & $3.9 \pm 2.0$ \\
\hline C & $25.3 \pm 4.9^{\Delta}$ & $330.1 \pm 12.3$ & $410.5 \pm 10.1$ & $597.4 \pm 18.2$ & $884.5 \pm 21.6$ & $4.3 \pm 2.9$ \\
\hline D & $23.1 \pm 2.7^{\Delta}$ & $223.6 \pm 6.6$ & $274.5 \pm 6.3$ & $373.9 \pm 7.0$ & $534.1 \pm 7.0^{*}$ & $39.3 \pm 5.2$ \\
\hline
\end{tabular}

${ }^{\star}$ Group D compared with groups $A, B$ and $C, p<0.05 ; ~ "$ group $A$ compared with groups $B, C$ and $D, p>0.05 .{ }^{\Delta}$ No difference in each group on $0 d, p>0.05$. 
A

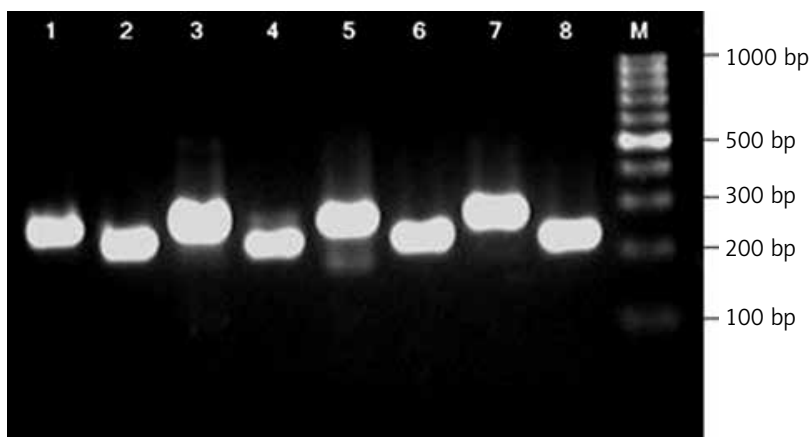

M: Marker, 1, 3, 5 and 7: $\beta$-actin (298 bp); 2, 4, 6 and 8: c-myc (220 bp); lane 1 and 2: control group; lane 3 and 4: CGUS group; lane 5 and 6: CG group; lane 7 and 8: CUS group.

B

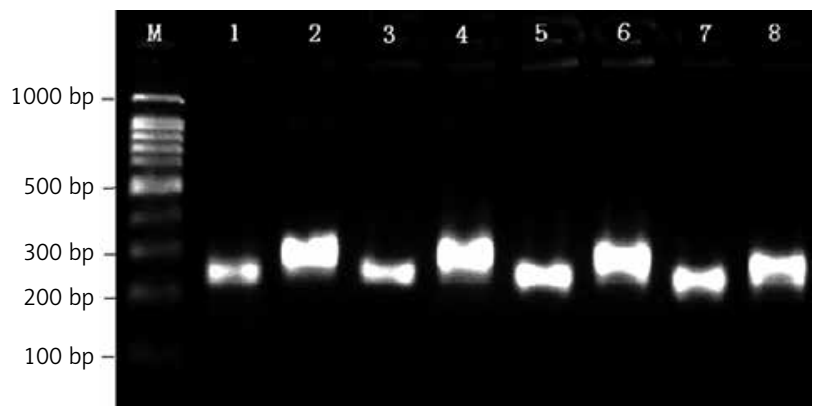

M: Marker, 2, 4, 6 and 8: $\beta$-actin (298 bp); 1, 3, 5 and 7: c-myc (220 bp); lane 1 and 2: CGUS group; lane 3 and 4: CUS group; lane 5 and 6: CG group; lane 7 and 8: control group.

Figure 9. Downregulation of c-myc mRNA in SMMC7721 cells. Expression of c-myc mRNA was determined by RT-PCR. Total RNA was reverse transcribed and amplified by the primers from $c-m y c$ and $\beta$-actin, and the polymerase chain reaction products were separated on $2 \%$ agarose gel. $\mathrm{A}-$ in vitro; $\mathrm{B}-$ in vivo.

gene expression compared with other groups $(p<0.05)$. These results indicated that $c-m y c$ ASODN could be delivered to SMMC7721 cells by G-PLL targeted SonoVue and ultrasound exposure, which inhibited c-myc gene expression. The expression of the $c$-myc gene in the three experimental groups was significantly lower than that in the control group in vitro $(p<0.05)$; however, there was no significant difference in the expression of $c-m y c$ between groups CG and CUS and the control group in vivo $(p>0.05)$, suggesting that $c-m y c$ ASODN without the G-PLL ligand or ultrasound cavitation effect could not play a therapeutic role in vivo.

\section{Discussion}

The key step of gene therapy is the successful transfer of therapeutic genes to targeted cells with safe and efficient expression. Targeted microbubbles constructed with a suitable conjugated ligand can specifically combine with the targeted tissue. After being modified with different methods, microbubbles might be selectively bound to specific organs, such as reticuloendothelial tissues [21]. Unger et al. [22] reported that constructing a targeted ligand with fibroblast growth factor (FGF) on the surface of microbubbles could increase the gene transfection efficiency.

The critical step in the preparation of targeted ultrasound microbubbles is to choose an appropriate ligand, which is integrated on the surface of microbubbles. In the present study, the targeted ligand G-PLL for liver cells was conjugated to the microbubbles, and the G-PLL microbubble model was successfully constructed; microbub-

Table II. Effects of different methods on the inhibition rate of $c$-myc mRNA

\begin{tabular}{|lcc|}
\hline Transfection methods & \multicolumn{2}{c|}{ Transfection rate, $\%(n=5)$} \\
\cline { 2 - 3 } & In vivo & In vitro \\
\hline Control group & 0 & 0 \\
\hline c-myc ASODN + G-PLL group & $2.35 \pm 0.54$ & $23.91 \pm 1.7$ \\
\hline c-myc ASODN + US group & $5.99 \pm 1.90$ & $23.93 \pm 2.6$ \\
\hline c-myc ASODN + G-PLL + US group & $30.84 \pm 2.26$ & $45.52 \pm 0.9$ \\
\hline
\end{tabular}

Values are expressed as mean $\pm S D$. 
bles containing the therapeutic gene specifically combined with liver cells, and following ultrasonic irradiation they generated cavitation effects to allow the c-myc ASODN to enter the cell cytoplasm. Our results showed that expression of the c-myc gene was significantly inhibited in the CGUS group in both in vivo and in vitro studies (Figure 9).

Receptor-mediated gene transfer technology is a method by which specific exogenous substances are transferred into the cell. Previous reports have indicated that SonoVue could be a useful gene delivery tool [23]. In our study, there were significant differences in expression of the $c-m y c$ gene between the experimental groups and the control group in vitro, suggesting that G-PLL played a critical role in targeting ligands mediated by the ASGP receptor. However, there was no significant difference in the expression of c-myc between groups CG and CUS and the control group in vivo, indicating that c-myc ASODN without the G-PLL ligand or ultrasound cavitation effect could not play a therapeutic role in vivo.

The main technical problem concerning the construction of targeted microbubbles was how to effectively connect relative ligands to the shell of microbubbles. The degree of conjugation would directly affect the transduction efficiency. Currently, the connection methods between the ligand and microbubbles are mainly divided into covalent bonding and non-covalent bonding (e.g. biotin-streptavidin, flexional multimeric space arm) [24]. Avidin-biotin interaction involves the strongest non-covalent bonds, widely used in biomedical research due to their unique high affinity [25]. Klibanov et al. [26] found that the higher the content of biotin on microbubbles, the stronger the binding strength between microbubbles and targeted tissue. When the content of biotin reached $7.5 \%$, microbubbles could not be washed away even in flowing water. Lindner et al. [27] targeted microbubbles against P-selectin by conjugating monoclonal antibodies against murine P-selectin to the surface of lipid-shelled microbubbles via a biotin-streptavidin system. Intravital microscopy showed that the binding efficiency of this kind is four times that of the control group. The avidin-biotin interaction can also be used to develop targeted therapies by the biotinylation of ligands in vivo [28]. In the present study, in order to ensure the close interaction between microbubbles and ligands, we applied the biotin-streptavidin system as a bridge, then G-PLL and c-myc ASODN could be tightly linked to microbubbles. El-Din et al. reported that some kinds of gene mutations such as the $\mathrm{p} 53$ gene are not associated with carcinogenesis or a high risk of future development of HCC [29]. Therefore, as indicated in our study, the specific binding of G-PLL and the c-myc gene in the liver cell might be critical in both experimental and clinical settings.

The development of targeted ultrasound microbubbles has achieved certain results, but it is still in the initial stage of exploration. From bedside to clinical application, several issues exist in this field. For one thing, the construction steps of microbubbles are complex, with a low stability and targeting rate, and the biotin-streptavidin system has some immunogenicity. All of these limit the coupling scheme only to the preclinical research [30]. Therefore, it is necessary to explore a better method of conjugation. Also, the ultrasound cavitation effect is related to the dose of microbubble contrast agent and ultrasound irradiation energy, frequency and other factors [31]. Adjustment of ultrasonic parameters could control the drug release rate and allow implementation of real-time monitoring. There are also some harmful biological effects through using UTMD to promote gene targeted therapy, which requires more in-depth studies [32]. In addition, a novel gene delivery system such as cationic liposomal microbubbles and ultrasound has been confirmed to enhance the image quality compared to SonoVue [33]. However, whether this technique can be applied to in vivo studies in humans and the safety of such techniques require future study. In the present study, G-PLL was the ASGP-R specific ligand on the surface of liver cells; therefore, it might also conjugate in healthy liver cells, not limited to hepatoma cells. Future study is also required to find a more specific target only expressed in hepatocellular carcinoma cells, but not in most healthy organs.

In this study, we constructed an effective ultrasound microbubble model targeting liver cells to improve the gene transfection efficiency. This also provided a theoretical basis for an effective, targeted and non-invasive gene therapy for hepatoma. With the development of ultrasound contrast agents and the related equipment, we believe it may present a novel and attractive gene therapy for liver cancer.

\section{Acknowledgments}

This work is supported by the National Natural Science Foundation of China (Project No. 81371568). Wen Cheng received the funding.

\section{Conflict of interest}

The authors declare no conflict of interest.

\section{References}

1. Andrisani OM, Studach L, Merle P. Gene signatures in hepatocellular carcinoma (HCC). Semin Cancer Biol 2011; 21: 4-9. 
2. Puneet P, Perera MT, Mirza DF. Current opinion on the role of resection and liver transplantation for hepatocellular cancer. Indian J Gastroenterol 2012; 31: 89-99.

3. Islam MNM, Azad SA, Karim E, Rahman SM, Khan NA. Interventional radiology for the treatment of hepatic malignancy. Mymensingh Med J 2012; 21: 377-90.

4. Guo WX, Sun JX, Cheng YQ, et al. Percutaneous radiofrequency ablation versus partial hepatectomy for smal centrally located hepatocellular carcinoma. World I Surg 2012; 11: 914-21.

5. Gregorevic P, Blankinship MJ, Allen JM, et al. Systemic delivery of genes to striated muscles using adeno-associated viral vectors. Nat Med 2004; 10: 828-34.

6. Oberle V, de Jong G, Drayer J, Hoekstra D. Efficient transfer of chromosome-based DNA constructs into mammalian cells. Biochim Biophys Acta 2004; 1676: 223-30.

7. Li X, Wang Z, Ran H, et al. Experimental research on therapeutic angiogenesis induced by hepatocyte growth factor directed by ultrasound-targeted microbubble destruction in rats. J Ultrasound Med 2008; 27: 453-60

8. Kang J, Wu X, Wang Z, et al. Antitumor effect of docetaxel-loaded lipid microbubbles combined with ultrasound-targeted microbubble activation on VX2 rabbit liver tumors. J Ultrasound Med 2010; 29: 61-70.

9. Ferrara K, Pollard R, Borden M. Ultrasound microbubble contrast agents: fundamentals and application to gene and drug delivery. Annu Rev Biomed Eng 2006; 9: 415-47.

10. Dollet B, van der Meer SM, Garbin V, et al. Nonspherical oscillations of ultrasound contrast agent microbubbles. Ultrasound Med Biol 2008; 34: 1465-73.

11. Juffermans LJM, Kamp O, Dijkmans PA, et al. Low-intensity ultrasound-exposed microbubbles provoke local hyperpolarization of the cell membrane via activation of BK"C"a channels. Ultrasound Med Biol 2008; 34: 7-17.

12. Qiu Y, Zhang C, Tu J, Zhang D. Microbubble-induced sonoporation involved in ultrasound-mediated DNA transfection in vitro at low acoustic pressures. J Biomech 2012; 45: 1339-45.

13. Delalande A, Postema M, Mignet N, et al. Ultrasound and microbubble-assisted gene delivery: recent advances and ongoing challenges. Therap Deliv 2012; 3: 1199-215.

14. Shimamura M, Sato N, Taniyama Y, et al. Development of efficient plasmid DNA transfer into adult rat central nervous system using microbubble-enhanced ultrasound. Gene Ther 2004; 11: 1532-9.

15. Xenariou S, Griesenbach U, Liang HD, et al. Use of ultrasound to enhance nonviral lung gene transfer in vivo. Gene Ther 2007; 14: 768-74.

16. Bekeredjian R, Kuecherer HF, Kroll RD, Katus HA. Ultrasound-targeted microbubble destruction augments protein delivery into testes. Urology 2007; 69: 386-9.

17. Meier M, Bider MD, Malashkevich VN. Crystal structure of the carbohydrate recognition domain of the $\mathrm{H} 1 \mathrm{sub}$ unit of the asialoglycoprotein receptor. J Mol Biol 2000; 300: 857-65.

18. Terada T, Iwai M, Kawakami S, et al. Novel PEG-matrix metalloproteinase-2 cleavable peptide-lipid containing galactosylated liposomes for hepatocellular carcinomaselective targeting. J Control Release 2006; 111: 333-42.

19. Pastorino F, Brignole C, Marimpietri D, et al. Targeted liposomal c-myc antisense oligodeoxynucleotides induce apoptosis and inhibit tumor growth and metastases in human melanoma models. Clin Cancer Res 2003; 9: 4595-605.

20. Han X, Cheng W, Jing $\mathrm{H}$, et al. Neuroepithelial transforming protein 1 short interfering RNA-mediated gene silencing with microbubble and ultrasound exposure inhibits the proliferation of hepatic carcinoma cells in vitro. J Ultrasound Med 2012; 31: 853-61.

21. Mayer CR, Geis NA, Katus HA, Bekeredjian R. Ultrasound targeted microbubble destruction for drug and gene delivery. Expert Opin Drug Deliv 2008; 5: 1121-38.

22. Unger EC, Hersh E, Vannan M. Gene delivery using ultrasound contrast agents. Echocardiography 2001; 18 355-61.

23. Zhou J, Want Y, Xiong Y, et al. Delivery of TFPI-2 using ultrasound with a microbubble agent (SonoVue) inhibits intimal hyperplasia after balloon injury in a rabbit carotid artery model. Ultrasound Med Biol 2010; 36: 1876-83.

24. Unnikrishnan S, Klibanov AL. Microbubbles as ultrasound contrast agents for molecular imaging: preparation and application. AJR Am J Roentgenol 2012; 199 292-9.

25. Wilchek M, Bayer EA, Livnah O. Essentials of biorecognition: the (strept)avidin-biotin system as a model for protein-protein and protein-ligand interaction. Immunol Lett 2006; 103: 27-32.

26. Klibanov AL, Hughes MS, Marsh JN, et al. Targeting of ultrasound contrast material. An in vitro feasibility study. Acta Radiol Suppl 1996; 412: 113-20.

27. Lindner JR, Song J, Christiansen J, et al. Ultrasound assessment of inflammation and renal tissue injury with microbubbles targeted to P-selectin. Circulation 2001; 104: 2107-12.

28. Lesch HP, Kaikkonen MU, Pikkarainen JT, Ylä-Herttuala S. Avidin-biotin technology in targeted therapy. Expert Opin Drug Deliv 2010; 7: 551-64

29. El-Din HG, Ghafar NA, Saad NE, et al. Relationship between codon 249 mutation in exon 7 of p53 gene and diagnosis of hepatocellular carcinoma. Arch Med Sci 2010; 6: 348-55.

30. Klibanov AL. Preparation of targeted microbubbles: ultrasound contrast agents for molecular imaging. Med Biol Eng Comput 2009; 47: 875-82.

31. Rahim A, Taylor SL, Bush NL, et al. Physical parameters affecting ultrasound/microbubble-mediated gene delivery efficiency in vitro. Ultrasound Med Biol 2006; 32 1269-79.

32. Haarter GR. Ultrasonic contrast agents: safety considerations reviewed. Eur J Radiol 2002; 41: 217-21.

33. Liu F, Zhu J, Huang Y, et al. Contrast imaging and gene delivery through the combined use of novel cationic liposomal microbubbles and ultrasound in rat carotid arteries. Arch Med Sci 2013; 20: 347-53. 